\title{
Editorial
}

\section{Discounting, inequality, and avoidability in health and illness}

In this number a non-economist questions the influence of economic customs and practices in assessing the effectiveness of health services and preventive activity. As another non-economist I have been puzzled by uncomprehending responses from some economists to my questions about the rationale and justification of discounting - not in principle but in practice, and in particular the rates of discounting. Answers have often been along the lines of "it's the custom".

Such questions are far from academic when we are struggling to evaluate the performance of health services, either in specific activities or as whole systems. Two papers in this number consider what has come to be called avoidable mortality in the context of whole health service operations. The conclusions from Sweden and Spain are not quite the same but are certainly cause for reflection.

A major theme in this number relates to inequalities in health and illness (especially heart disease) and in general and specific influences on or risks for health. Information ranges internationally from the US through the UK into the Nordic countries. Approaches vary from considering social networks to bereavement and unemployment and race and physical activity, and from mathematical modelling to self reported health.

If we are serious in using epidemiology and other population-based approaches to influence the public health, we have no option but to combine rigorous methods with tough political discussion and action. This is well illustrated by our historical article and its author's reflections on 20 years of action in the realm of smoking and health, ranging from randomised controlled trials to individualistic and formal political activity.

Our task is indeed to bring together epidemiology (and related disciplines) and community health (and social medicine and public health).

STUART DONNAN 